\title{
Polypharmacy and the coproduction of the experience between physicians and patients
}

\section{Polifarmácia e a coprodução da experiência entre médicos e pacientes}

\author{
Md Mafuzul Huq \\ Universidade Federal do Rio de Janeiro - UFRJ - Brasil e \\ EAESP FGV - Brasil \\ mdmafuzulhuq@gmail.com \\ ORCID: https://orcid.org/0000-0002-6278-0263 \\ Julie Maryne Fingolo \\ Universidade Federal do Rio de Janeiro - UFRJ - Brasil \\ julie.maryne@coppead.ufrj.br \\ ORCID: https://orcid.org/0000-0001-9318-933X \\ Claudia Affonso Silva Araujo \\ Universidade Federal do Rio de Janeiro - UFRJ - Brasil \\ claraujo@coppead.ufrj.br \\ ORCID: https://orcid.org/0000-0003-0290-4807
}

Recebido: 26 Março 2021
Revisado: 10 Maio 2021
Aceito: 19 Agosto 2021

\begin{abstract}
Purpose: To identify how physicians can help polypharmacy patients deal with their disease condition by focusing on the non-clinical factors of care processes. Therefore, this study aims to answer the following specific questions: (1) What are the causes of polypharmacy? (2) How do patients experience the consequences of polypharmacy? (3) How can the service coproduction concept help physicians manage and reduce polypharmacy? Methodology: We applied a qualitative exploratory study. Data were collected by in-depth interviews, and the material was analyzed considering three coproduction dimensions - knowledge, skills, and motivation. Main results: This research found that several non-clinical factors may cause polypharmacy and trigger problematic phenomena. Accordingly, several initiatives that add value for patients who are in polypharmacy were suggested. Academic contributions: This research increases the knowledge about the non-clinical polypharmacy factors and possible initiatives to mitigate this condition. It is also essential because there are few studies focused on this subject in developing countries like Brazil. Practical contributions: This study proposed several interventions that physicians can use to manage polypharmacy.
\end{abstract}

Keywords: Healthcare; polypharmacy; non-clinical factors; value for patients; coproduction

\section{Resumo}

Objetivo: Identificar como os médicos podem ajudar seus pacientes em polifarmácia ao focar nos fatores não-clínicos do processo do cuidado. Para isso, essa pesquisa objetiva responder as seguintes perguntas: (1) Quais são as causas da polifarmácia? (2) Como os pacientes experienciam as consequências da polifarmácia? (3) Como o conceito de coprodução pode ajudar os médicos a gerenciar e reduzir polifarmácia? Metodologia: Foi utilizada uma abordagem fenomenológica e dados qualitativos. Os dados foram coletados em entrevistas em profundidade e o material foi analisado com base em três dimensões da coprodução - conhecimento, capacidade e motivação. Principais resultados: Essa pesquisa revelou que muitos fatores não-clínicos podem causar a polifarmácia e desencadear fenômenos problemáticos para pessoas nessa condição. Para solucionar esse problema, algumas iniciativas que agregam valor ao paciente foram sugeridas. Contribuições acadêmicas: Essa pesquisa contribuiu para o aumento do conhecimento sobre os fatores não-clínicos da polifarmácia, além de trazer possíveis iniciativas para mitigar essa condição. Também é essencial para o meio acadêmico por existirem poucos estudos focados na polifarmácia em países subdesenvolvidos como o Brasil. Contribuições práticas: Esse estudo propôs diversas intervenções que podem ser usadas pelos médicos como maneira de gerenciar essa condição.

Palavras-chave: Saúde; polifarmácia; fatores não-clínicos; valor para o paciente; coprodução

\section{Introduction}

In healthcare services, patients' value perception depends not only on clinical treatment results but also on several non-clinical perspectives that refer to the social, economic, and ecological 
environments and influence the patient's care process (Duerden \& Payne, 2013; Dadfar et al., 2013). Among non-clinical factors are patients' and physicians' communication and cooperation, patients' quality of life experienced in a medical regimen, and patients' financial ability to afford the treatment (Duerden \& Payne, 2013; Duffett, 2017).

Also, patients' living environment may hamper or facilitate treatment adherence (Dadfar et al., 2013; Batalden et al., 2016). Therefore, physicians' role is to understand those environments and support patients (Dadfar et al., 2013). Duffett (2017) added that whereas healthcare professionals have disease-specific expertise, patients have experience-based expertise. For this reason, exploring non-clinical perspectives of care processes can be a driving force in managing polypharmacy. In this regard, it is important to note that customers engage in a learning process based on their experience during service encounters, which informs their decision on how to coproduce their experience with the supplier. In turn, the provider is also learning. The more the provider learns about the customer, the more he will be able to improve the design of the experience and enhance cocreation with customers (Payne, Storbacka and Frow, 2008).

Regarding service coproduction, Damali et al. (2016) state that customers should have the knowledge, skills (capabilities), and motivation (willingness) to participate in the service process and coproduce value. The authors argue that knowing what to do is positively correlated with role clarity. Moreover, patients should have the skills (know-how) to perform the tasks. Finally, patients should know the benefits of performing a service task. These authors argue that knowing why is positively correlated with customer motivation to perform their task.

In this context, this research aims to identify how physicians can help polypharmacy patients deal with their disease's adverse effects by focusing on the non-clinical factors of care processes. Therefore, this study aims to answer the following specific questions: (1) What are the causes of polypharmacy? (2) How do patients experience the consequences of polypharmacy? (3) How can the service coproduction concept help physicians manage and reduce polypharmacy? Polypharmacy patients are those that take at least five medications a day (Hovstadius et al., 2009), and the analysis regarding the appropriate initiatives to manage and reduce polypharmacy was done considering the three dimensions proposed by Damali et al. (2016): initiatives directed to improve patients' knowledge, skills, or motivation.

The research findings will contribute to the understanding of non-clinical aspects relevant for the care delivery process in polypharmacy conditions and designing interventions that will provide value for patients and make the healthcare services more efficient. Moreover, the findings can generate insights for existing and potential researchers who seek scholarly works on polypharmacy.

\section{Literature review}

\subsection{Polypharmacy}

Polypharmacy refers to prescribing multiple medicines to an individual (Masnoon et al., 2017). However, the discussion on polypharmacy reveals that medical literature lacks a clear and uniform definition of it. Hovstadius, Åstrand and Petersson (2009) state that polypharmacy patients take at least five medications, excluding over-the-counter (OTC) medications - the medicines a person can buy without a prescription - and devices and externally used substances (e.g., pomades). They reasoned that the cutoffs are the same in most polypharmacy studies; thus, this deliberate action will enable comparisons with other studies. This study will follow this definition.

Polypharmacy has been associated with several adverse consequences like poor medication adherence (Benetos et al., 2015; Gupta, 2019; Hasan Ibrahim et al., 2021), adverse drug events (ADEs), increase in the number of outpatient and emergency room visits (Gupta, 2019; Tecklenborg et al., 2020), and drug-drug severe interactions (Herr et al., 2017; Mair et al., 2020; Masnoon et al., 2017). Therefore, polypharmacy can increase health services utilization and costs, generating a high economic burden (Köberlein et al., 2013; Bradley et al., 2012; Pappa et al., 2011). Moreover, MontielLuque et al. (2017) and Riker \& Setter (2013) argue that polypharmacy patients experience poor quality of life, including physical and social function.

Polypharmacy predictors include clinical and non-clinical factors. Clinical factors are out of this research scope. Therefore, we focused on non-clinical factors that can cause polypharmacy. For example, smokers are likely to experience this condition (Abolhassani et al., 2017) because they are more likely to suffer from multiple diseases, which require various medications (Pappa et al., 2011). Also, obese individuals are more exposed to numerous drug treatments since obesity can deteriorate individuals' quality of life and correlate with many chronic diseases (Pappa et al., 2011; Degli et al., 2006). 
Self-medication and receiving advice from friends and relatives also induce polypharmacy (Anthierens et al., 2010; Secoli et al., 2018). Additionally, self-administered medications may cause side effects, poor adherence to prescribed medicines, and increase morbidity and mortality (Secoli et al., 2018; Anthierens et al., 2010). Finally, medication disagreement between doctors and patients is a known predictor of polypharmacy (Junius-Walker, 2007; Anthierens et al., 2010).

Regarding physicians, prescribers' lack of pharmacological knowledge induces polypharmacy (Anthierens et al., 2010). Moreover, prescribers' attitudes toward polypharmacy may broaden polypharmacy cases. Larson (2001) and Anthierens et al. (2010) mention that some physicians do not consider polypharmacy a critical phenomenon. As a result, it is easy to start a new treatment for every new complaint without evaluating the existing medication schedule.

Besides, multiple doctors are likely to cause polypharmacy since each provider might treat a patient from their own specialties' perspective (Anthierens et al., 2010; Hirose et al., 2021). Larson (2001) argues that one prescriber might be reluctant to interfere with the treatment prescribed by another physician because of deference, and patients' medication intake is not optimized.

Clinicians and the healthcare system face challenges in managing polypharmacy globally (Guthrie et al., 2015). Guthrie et al. (2015) argue for optimizing medication regimens through regular medications review. Anthierens et al. (2010) advocate for a treatment coordinator to optimize patients' medication if multiple providers cause polypharmacy. They also propose that prescribers need training on pharmacotherapy. Guthrie et al. (2015) argue that prescribers should develop skills in applying the acquired knowledge. Furthermore, Spinewine et al. (2007) propose a multidisciplinary approach in which prescribers, patients, and cares work closely to address polypharmacy's adverse effects. In turn, Hasan Ibrahim et al. (2021) propose practice-based pharmacists' services to optimize medication management. Finally, Anthierens et al. (2010) argue that prescribers should consider polypharmacy as a negative approach and be proactive in reducing polypharmacy cases.

\subsection{Coproduction - An effective approach to manage polypharmacy}

Elinor Ostrom and her colleagues introduced the concept of coproduction in the 1970s, arguing that the production of public services and effective service delivery require collaboration between professional providers and service users (Ostrom et al., 1978; Rosentraub and Sharp, 1981).

This concept evolved and was introduced in the healthcare literature (Marsilio et al., 2021). For example, Spanjol et al. (2015) examined consumer coproduction in the context of medication adherence by chronically diseased patients. According to these authors, coproduction systems are contextual, and patients' motivations and capabilities are key determinants of adherence to medical treatment. In turn, Batalden et al. (2016) proposed a model for coproduction in healthcare service in which patients and professionals interact as participants within a healthcare system in society that supports and constrains effective partnership.

Damali et al. (2016) state that customers should have the knowledge, skills (capabilities), and motivation (willingness) to participate in the service process and coproduce value. The authors argue that knowing what to do is positively correlated with role clarity. Moreover, patients should have the skills (know-how) to perform the tasks. Finally, patients should know the benefits of performing a service task. These authors argue that knowing why is positively correlated with customer motivation to perform their task.

Dellande et al. (2004) propose three factors as necessary for the consumer to cooperate, coproduce and co-create value in the healthcare service: role clarity - knowledge and understanding of what needs to be done, what activities need to be performed; ability - customers' ability to do what they are supposed to do; and motivation - incentives that consumers have to play their role. These four dimensions are aligned to Damali et al.'s (2016) perspective that customers should have the knowledge, skills (capabilities), and motivation (willingness) to participate in the service process and co-create value. Likewise, Jaspers and Steen (2020) state that a mutual commitment is necessary for coproduction and point at the need to sustain coproducers' ability, motivation, and opportunity, arguing that these conditions are crucial not only for making coproduction occur but also for sustaining it.

Regarding patients-physician coproduction of the healthcare service, Duerden and Payne (2013) argue that doctors should stimulate patients to report their polypharmacy experiences. Craig (2015) states that it is essential to reveal what matters to patients when they are in this condition. In this sense, physicians can adopt some strategies to avoid polypharmacy. For example, asking patients to bring all medications to their medical appointments may help physicians verify if patients are taking the right drugs and review possible interactions (Haque, 2009; Rozenfeld, 2003). Also, having patients' feedback about the medications taken (Hirose et al., 2021) and their active engagement in decision- 
making about their medicines (Hasan Ibrahim et al., 2021) may help physicians understand patient's life and decrease the number of medications prescribed.

Creating a drug flow record or an integrated prescription record (Hoel et al., 2021) and having healthcare professional cooperation (Hirose et al., 2021) could also mitigate duplicates or interacting medications prescribed for their patients. Besides, preference for single-drug or single pills can minimize the number of prescribed drugs, avoid polypharmacy, and increase patients' quality of life (Haque, 2009; Rozenfeld, 2003; D'Avanzo et al., 2020; Endsley, 2018; Jansen et al., 2016). Some tools compare a patient's medication list to a set of potentially inappropriate medications and allow to check for medication duplication, drug interactions, and medication adjustments required for specific disease states - e.g., STOPP - screening tool of older people's prescriptions, and START - screening tool to alert to proper treatment (O'Mahony et al., 2015; Stewart et al., 2017).

Also, the joint effort between patients and physicians, coproducing health treatments, is an essential element of service operation management in healthcare service that makes care more consistent with the patient's health-related needs (Payne et al., 2008; McColl-Kennedy et al., 2012; Palumbo, 2016). According to Palumbo (2016), coproduction in the healthcare sector is associated with patient empowerment and involvement, patient-centered care, and self-management of care. This association makes clear that coproduction in healthcare is an approach that involves patients at the heart of service design and delivery to make the provision of care more consistent with the patients' health-related needs (Knowles et al., 2018; Palumbo, 2016; McColl-Kennedy et al., 2012).

Therefore, coproduction should become the primary approach to manage polypharmacy. Coproduction mobilizes customers and ensures resource and tacit knowledge to deliver the required output (Frei, 2008; Chan et al., 2010). Moreover, patients in polypharmacy are different in terms of their medical conditions and therapies. Therefore, their care should be individualized.

Coproduction activities may increase the efficiency of polypharmacy patients' treatment. For instance, the patients and the healthcare professionals can share mutual information improving physicians' diagnosis and allowing the definition of a joint strategy to deal with illness (Palumbo, 2016). Moreover, physicians can share the decision-making process with patients to ensure that decisions are focused on the patient's circumstances and values (Bradley, 2015), making patients more comfortable with the decisions made about their care (Coulter, 2009). Furthermore, physicians can use patients' inputs to develop new therapies (Mustak et al., 2013) or enhance outcomes and experiences for carers and service users (Bradley, 2015). Additionally, physicians may experience relational value in friendly, respectful, and attentive communication with patients, which, in turn, may improve physicians' job satisfaction (Hee Yoon et al., 2004). However, coproduction initiatives in managing polypharmacy can be a double-edged sword: it can benefit patients and physicians, but it can also yield negative consequences such as increasing physicians' job stress (Chan et al., 2010).

Coproduction is a social exchange, which accommodates people's norms, roles, and expectations, which, in turn, are influenced by each party's cultural background (Patterson et al., 2006). Therefore, coproduction benefits depend on how well patients and physicians adapt to the newly defined social behaviors (Youngdahl et al., 2003). Coproduction will likely flourish among collectivist value-oriented people because they will adjust their actions in roles that facilitate cooperation and personal connections (Stryker, 2006). On the other hand, high individualist value-oriented people prefer rewards that are proportional to their contributions. They are more likely to be involved in a business relationship. They are less concerned about building a personal relationship (Chan et al., 2010) and, thus, are inappropriate candidates for coproducing initiatives.

Coproduction might heighten physicians' job stress and lower their job satisfaction, increasing the loss of power and control, input uncertainty, and incompatibility in expectations and demands (Chan et al., 2010). Coproduction allows the patient to gain control of their wellbeing (Aujoulat et al., 2012). The loss of power and authority may trigger a role incongruence. Physicians perceive disruption in the smooth functioning of the service process, and this perceived disruption might induce them to struggle with patients for control (Chase, 2010). As the degree and quality of patients' inputs can vary considerably (Mustak et al., 2013), physicians may perceive greater demand diversity, which will trigger uncertainty (Duerden \& Payne, 2013). This added uncertainty might ultimately hamper their job satisfaction and increase their job stress (Chan et al., 2010).

Therefore, every simulation of coproducing initiatives may not benefit patients and physicians. Additionally, it can overwhelm service scripts and jeopardize the treatment process. Physicians must understand how to harness the benefits and limit the drawbacks (Chan et al., 2010). They may need to adopt some practical actions and remain sensitive to their and patients' cultural values. In some cases, they may need to introduce cultural changes in their operations (Chan et al., 2010), introduce appropriate training and reward system to equip and motivate staffs (Mustak et al., 2013), select those staffs who are flexible, responsive and facilitate personal relationships, diversify special cases and 
motivate and train patients to embrace coproduction and develop abilities to follow prescribed behaviors (Chan et al., 2010). Motivation and training are particularly important for care processes that are more complex and contain situations that are less familiar to patients (Chan et al., 2010).

\section{Methodology}

We applied a qualitative phenomenological approach to identify how physicians can help polypharmacy patients deal with the adverse effects related to this condition (Combrinck et al., 2020). In addition, we focus on non-clinical factors of care processes.

Considering that this is an exploratory study, we tried to interview people that could cover different perspectives on the topic (Prasad, 2005). Therefore, we interviewed six persons: four patients and two physicians. The selected patients take at least five medicines per day, live in Brazil, and suffer from multiple chronic diseases. The physicians work in a health insurance company located in Sao Paulo, Brazil, that provides clinical treatment to elderly polypharmacy patients. These interviewees were chosen because they met the research requirements and agreed to participate in the study. The authors are aware of the low number of respondents, but interviewing doctors in the health context is quite tricky, and finding patients suffering from polypharmacy willing to be interviewed mainly in a pandemic situation. Table 1 presents information about the interviewees.

Table 1 - Useful information about the respondents

\begin{tabular}{|c|c|c|c|c|c|}
\hline $\begin{array}{c}\text { Respondents } \\
\text { (pseudomonas name) }\end{array}$ & Category & Gender & Age & $\begin{array}{c}\text { Medication Intake } \\
\text { per day }\end{array}$ & Medical Condition \\
\hline PA1 & Patients & Female & 76 & 14 & $\begin{array}{c}\text { Blood pressure; Heart } \\
\text { disease; Asthma }\end{array}$ \\
\hline PA2 & Patients & Female & 55 & 6 & Breast cancer \\
\hline PA3 & Patients & Female & 28 & 5 & $\begin{array}{c}\text { Depression; Mineral } \\
\text { deficiency }\end{array}$ \\
\hline PA4 & Patients & Male & 64 & 10 & $\begin{array}{c}\text { Blood pressure; Heart } \\
\text { disease }\end{array}$ \\
\hline PH1 & Physicians & Male & Not Known & Not applicable & Not applicable \\
\hline PH2 & Physicians & Male & Not Known & Not applicable & Not applicable \\
\hline
\end{tabular}

Source: Elaborated by the authors

Data were collected by conducting in-depth interviews with semi-structured open-ended interview scripts. We applied two separate interview scripts for the patients and the physicians. These scripts were developed based on the literature review. Patients' questions were focused on polypharmacy's consequences to their lives and how they believe physicians could help them deal with their disease and reduce the number of drugs. Physicians' questions focused on their understanding of polypharmacy causes and how they think they could help patients in this condition. Each interview lasted around sixty minutes. Interviews were recorded and transcribed by the first author.

Interviews' analysis was performed in a few steps, as Fitzpatrick and Boulton (1994) proposed. The first stage was to code and classify the collected material using Microsoft Excel. The next step was coding the material based on the three dimensions proposed by Damali et al. (2016). Thus, the interviewees' responses were analyzed to identify convergences and divergences between the interviewees' answers and the reviewed literature. The intention was to instigate a dialogue between the literature and the interviewees' perspective on causes, consequences, and how to manage polypharmacy. Therefore, we did not collect secondary data, as we were interested in the interviewees' views about the issue.

This research was approved by the Ethics and Research Committee of the Federal University of Rio de Janeiro.

\section{Findings}

This section is organized considering the three specific questions that this research intends to answer. 


\subsection{How do patients experience polypharmacy's consequences - how do they perceive, describe, feel, judge, remember, understand, and talk about it with others?}

This research found that polypharmacy triggered several consequences. Polypharmacy may induce non-compliance to medication guidelines since an excessive number of drugs can make patients forget doses and medicines' names. One of the critical implications of poor adherence is the disease's progress, as PA1 described: "if patients do not adhere to their treatment, the disease progresses, and this can cause evil effects because you are not treating the condition correctly".

Polypharmacy may also cause patients inappropriate behavior. They may be annoyed by the excessive number of medicines and skip doses. They may feel accomplished and stop taking the prescribed drugs. They may also be confused and try to remember their medications through their color, not a safe procedure.

Moreover, non-adherence may trigger other biological dysfunctions. Sometimes, patients do not experience the effects of non-adherence immediately but suffer afterward. The dysfunctions are a typical case for some medicines. PH2 said:

"Another thing is that polypharmacy can cause dysfunction in other organs - e.g., gastric, stomach issues. Depending on how long patients take the medicines, they may have a gastric intolerance, which generates gastritis".

Besides, polypharmacy may be problematic in emergency cases. PS1 recalled a situation when she needed emergency treatment, and the doctors assisting her did not know about her medications. Therefore, the prescribed treatment worse her health status because of medication interaction.

According to the interviewees, polypharmacy may deteriorate patients' quality of life. Fear of side effects is common among those patients because so many medications can be harmful to their bodies. In addition, excessive numbers of drugs can make patients forget to take the medicines because they are unhappy with taking multiple medications.

PA2 highlights the importance of trusting in the physician:

"My medical condition [breast cancer] is chronic. I have been taking those medicines for almost six years. It does not bother me. I think if you need to take, you have to take. Don't look at the supplements information on the label... it can make you more worried... trust your doctors and follows their recommendations".

On the other hand, PA3 argues that "it is not necessary to take so many medications. Physicians can manage our disease without pills because drugs are complementary. Medications can interfere with one's personality (...) and have side effects".

\subsection{What are the causes of polypharmacy?}

This research found that several non-clinical factors can induce polypharmacy. For example, visiting multiple providers can cause polypharmacy as physicians may not optimize the patient's medication intake. In turn, patients may remain unaware of the duplication and, as a consequence, take more medicines than is necessary. Because redundancy can lead to a loss of confidence in the physician, doctors should find which drugs are duplicated and correct this mistake.

Likewise, some lifestyles such as smoking, poor diet, and lack of exercise commonly induce polypharmacy since these conditions can expose individuals to multiple diseases and obesity. Beyond that, the country's culture, perspectives, and lack of government initiatives that encourage a healthier lifestyle greatly influence polypharmacy conditions. A person's family background also tends to contribute to the adoption of these lifestyles.

Moreover, accumulated multiple chronic conditions may trigger other medical conditions. Therefore, collateral medical effects, in which one dysfunction caused by a medical condition weakens other physiological functions and starts other medical conditions, are common among those individuals. Therefore, some patients need multiple medications to treat individual diseases and drugs to treat their side effects.

Also, self-medication may induce polypharmacy. This research found self-medication forms such as discontinuing prescriptions, following old prescriptions, skipping doses, and overdosing. One of the causes of self-medication is that patients receive medications from their physicians and well-wishers, such as friends, relatives, or neighbors. Besides, hypochondriacs are prone to self-medication as they are very anxious about their health condition and can increase doses or take different drugs. 


\subsection{How can the coproduction concept help physicians manage polypharmacy?}

According to the interviewees, several initiatives could minimize polypharmacy conditions. Considering the knowledge dimension proposed by Damali et al. (2016), patients' consciousness and knowledge about their disease and medications can help reduce the number of prescribed drugs because they are prepared to talk to their physicians and exchange ideas about their treatment and prescribed drugs. Thus, physicians should educate patients regarding medication intake and the harmful consequences of self-medication. The patients should know how multiple medication intake might affect them and what they should do in different circumstances. PH1 states that: "If you want to take care of the patient, the ideal is always to explain the purpose of the treatment and what can happen, leave everything written about what it will be like for the patient, and some medications".

Regarding the motivation and skill dimensions (Damali et al., 2016), an important initiative is to foment patients' trust in their doctors through a stronger patient-doctor relationship. In this sense, PA2 mentioned how she controls herself against hypochondriacs: "[...]the doctors know my lifestyle and advise me not to take medicines without a prescription. I first call him to see if I can take some medication or not". Besides, PH1 stated that poor diet, smoking, and a lack of exercise can induce multiple chronic diseases. Therefore, physicians should provide specific recommendations regarding those aspects and encourage patients to adopt a healthy lifestyle. Also, physicians should adopt a cooperative approach with their patients, sharing responsibilities about care decisions. Patients can help determine whether a particular treatment will be beneficial or problematic as physicians cannot force patients to be proactive. As PH1 mentioned:

"I indicate the treatment and explain what it is and how it works, but the patient needs to understand what it is... Only the patient can determine whether he should treat his condition. I cannot force the treatment, and I cannot keep up with all the patients I've prescribed something. I always say that treatment is a two-way street."

Furthermore, multiple providers tend to induce polypharmacy as they are unlikely to cooperate in optimizing patients' medication intake. Moreover, each provider can focus on their field of expertise, increasing the number of medications and the possibility of redundant drugs. Besides, polypharmacy patients may experience high treatment costs, unhappiness, and unpleasant feelings. They may also not comply with the medication guidelines or forget to take the pills. This research suggests that patients should receive combined pills in which several substances are merged in only one medication. To do that, a coordinator should look after patients' medication intake when they visit multiple providers. This coordinator can be any physician who is aware of the patients' medical history. This initiative might reduce the number of drugs and the corresponding adverse consequences. This plan would also improve patients' skills to follow the treatment.

\section{Discussion}

\subsection{The consequences of polypharmacy}

Polypharmacy induces non-compliance to medication guidelines (Benetos et al., 2015; Gupta, 2019; Hasan Ibrahim et al., 2021). Likewise, this research shows that an excessive number of drugs can make patients forget or skip doses.

This research indicates that patients' poor medication adherence may hamper the treatment and trigger other biological dysfunctions, reinforcing previous reviews (Montiel-Luque et al., 2017).

The polypharmacy patients interviewed mentioned they experience poor quality of life, including physical and social function, in line with previous research on the theme (Riker and Setter, 2013). The interviewees also mentioned the high cost of polypharmacy and its impact on the household budget, as indicated in the literature (Bradley et al., 2012; Pappa et al., 2011).

This research uncovered some more aspects that may also deteriorate the patients quality of life. Fear of side effects was common among the respondents (patients). Patients realize that too many medications can be a danger to their health. Moreover, polypharmacy may cause unhappiness since they have to accept their lives with multiple medications.

\subsection{The causes of polypharmacy}

Several factors induce polypharmacy. Visiting multiple providers is common to cause polypharmacy as specialization may generate redundancy in the patients' medication intake. In this regard, patients who do not receive an adequate treatment explanation remain unaware of the duplication, and consequently, they take more medicines than is necessary. This find reinforces previous studies (Anthierens et al., 2010; Hirose et al., 2021).

This research reinforces previous studies associating lifestyle to the polypharmacy condition (Pappa et al., 2011). The interviewees mentioned smoking, poor diet, drinking, lack of exercise, and 
obesity as causes of their polypharmacy condition. According to the interviewees, some factors might induce tobacco, poor diet and lack of exercise. Among these factors are the country's culture and the lack of government initiatives to encourage a healthier lifestyle.

This research also reveals that multiple chronic conditions might trigger other medical conditions. As a result, polypharmacy patients need various medications to treat each disease, generating adverse collateral effects.

Anthierens et al. (2010) and Secoli et al. (2018) mentioned that self-medication might induce polypharmacy. Likewise, the patients interviewed mentioned receiving medications from their physicians and relatives, neighbors, and friends. There was also one interviewee that said that hypochondria is a reason for self-medication. Other forms of self-medication identified in this research are discontinuing prescriptions, continuing outdated medical prescriptions, skipping doses, and overdosing.

\subsection{How can coproduction help manage polypharmacy?}

According to the interviewees, several initiatives may be taken to manage polypharmacy. First, patients' consciousness and knowledge should help prevent self-medication. Second, physicians should educate patients about their medication intake. Third, physicians should individualize treatments, understanding the treatment impact on patients' life. Moreover, patients' trust in their doctors may avoid circumstances that trigger hypochondriacs. These results reinforce the importance of value coproduction in healthcare services, as mentioned by Payne et al. (2008), McColl-Kennedy et al. (2012), Palumbo (2016), among others.

Another possible initiative identified in this research is to combine different pills to reduce the number of drugs prescribed and improve patients' adherence and quality of life. This result is aligned with previous studies (Rozenfeld, 2003). According to the physicians investigated, merged pills are not unrealistic, and some medicines have already been combined. However, they argue that the pharmaceutical industry may resist the proliferation of combined drugs, fearing a decrease in their companies' revenue. However, they believe some factors might reduce resistance. Combined pills may position the company as a unique provider in the market, allowing charging a premium price. Those market advantages would compensate for the potential losses. Manipulation pharmacies can also provide combined pills but not on a big scale.

The interviewed physicians also mentioned that having a treatment coordinator when patients visit multiple physicians can reduce polypharmacy. This coordinator would manage patients' medication prescribed by different providers. This initiative is also reported by Anthierens et al. (2010) and Guthrie et al. (2015).

Table 2 summarizes the findings regarding the possible strategies to reduce polypharmacy and relates these strategies to the three dimensions proposed by Damali et al. (2016) to foment customer coproduction and increase patient's adherence.

Table 2 - Research findings

\begin{tabular}{|c|c|}
\hline Polypharmacy Causes/Consequences & Possible Strategies and Damali et al. (2016) dimension \\
\hline $\begin{array}{l}\text { - } \quad \text { self-medication. } \\
\text { - } \quad \text { hypochondria. }\end{array}$ & $\begin{array}{l}\text { - Improving patients' prescription understanding - knowledge. } \\
\text { - Patient trust in their physicians - motivation. } \\
\text { - Coproduction - patient-physician relationship - skill and motivation. }\end{array}$ \\
\hline - $\quad$ multiple providers & - Using a coordinator physician - knowledge and skill. \\
\hline $\begin{array}{l}\text { - } \text { non-adherence to medication } \\
\text { guidelines } \\
\text { - } \quad \text { poor quality of life } \\
\text { patients' atypical behaviors }\end{array}$ & $\begin{array}{l}\text { - Preference for single drug / combined pills - skill and motivation. } \\
\text { - Use of tools like STOPP (screening tool of older people's prescriptions) } \\
\text { and START (screening tool to alert to right treatment) - skill. } \\
\text { - Creating a drug flow record or an integrated prescription record and } \\
\text { having health care professional cooperation - skill and motivation. } \\
\text { - Having patients' feedback about the medications taken - skill and } \\
\text { motivation. } \\
\text { - Coproduction - having patients' active engagement in decision-making } \\
\text { about their medicines - knowledge, skill, and motivation. } \\
\text { - Use of a coordinator physician - knowledge and skill. }\end{array}$ \\
\hline
\end{tabular}

Source: Elaborated by the authors 
This research identified some aspects that complement the coproduction literature related to adherence to medication. Polypharmacy has been associated with several adverse consequences such as adverse drug events, drug-drug interactions (Herr et al., 2017; Mair et al., 2020; Masnoon et al., 2017), and poor medication adherence (Benetos et al., 2015; Gupta, 2019; Hasan Ibrahim et al., 2021). However, the association between polypharmacy and those adverse consequences is not inherently linear. Some polypharmacy patients interviewed did not report suffering negative consequences regarding this condition. The polypharmacy adverse effects are context-specific and depend on the patient's physiology, health status, and medical conditions.

Figure 1 illustrates some identified initiatives that can be implemented to mitigate the leading polypharmacy causes. The arrows link the proposed initiatives to the polypharmacy causes.

\section{Figure 1 - Possible initiatives to mitigate the leading polypharmacy causes}

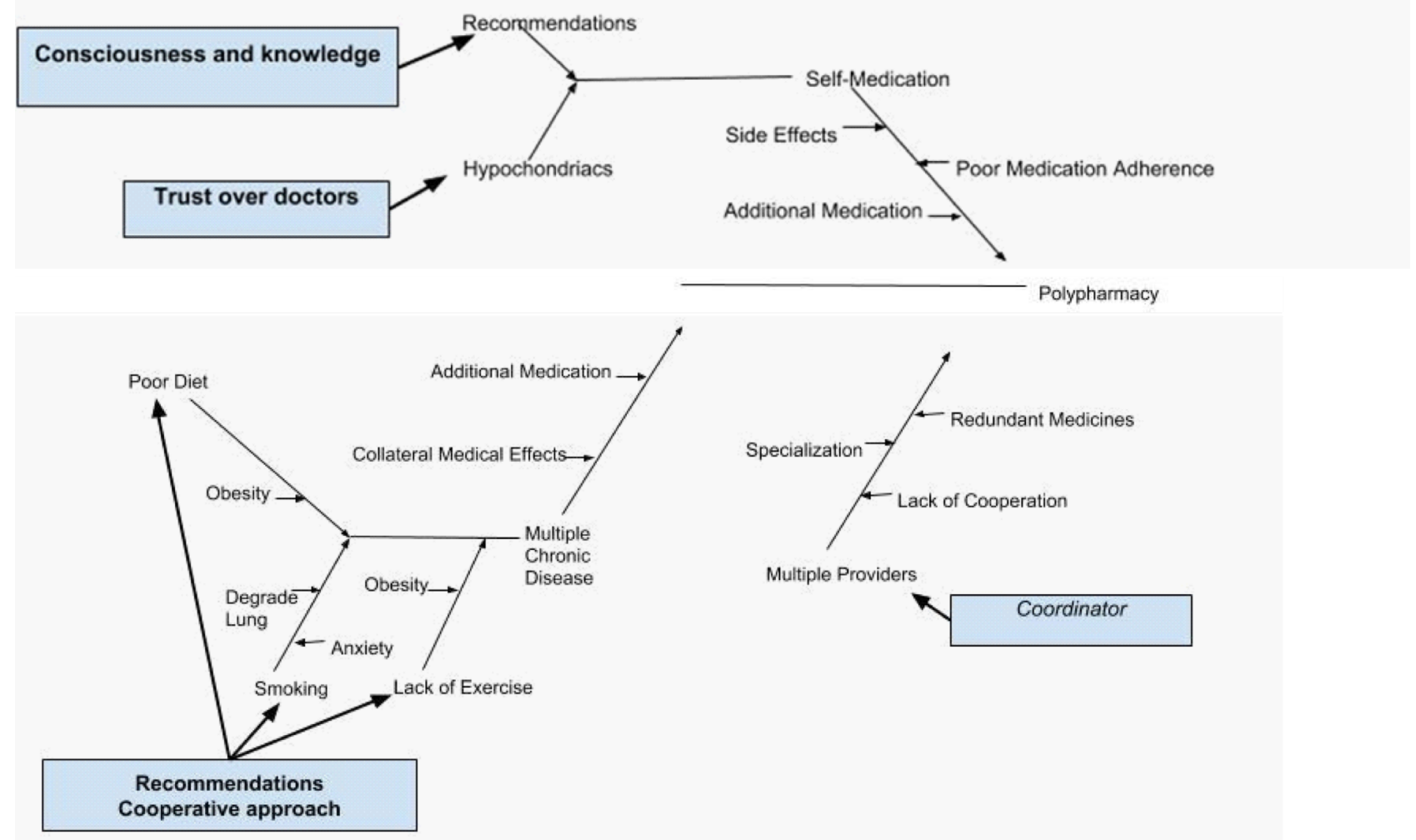

Source: Elaborated by the authors

This study also revealed some possible polypharmacy consequences: biological dysfunctions because of drugs interactions, poor quality of life, poor medication adherence, and difficulties in emergency cases. Figure 2 presents some initiatives to deal with these consequences. The arrows link the proposed initiatives to the polypharmacy consequences.

\section{Conclusion}

This research aimed to identify how physicians can help reduce polypharmacy cases or help patients in dealing with the adverse effects of this condition by focusing on non-clinical factors of polypharmacy. Therefore, this research answers three specific questions: (1) What are the causes of polypharmacy? (2) How do patients experience the consequences of polypharmacy? (3) What are the appropriate initiatives to manage and reduce polypharmacy?

This study elucidated that various factors can cause polypharmacy, like friend recommendation, hypochondria, unhealthy lifestyle, and multiple providers' assistance. Regarding possible initiatives to deal with polypharmacy consequences and how physicians can help reduce polypharmacy cases or assist patients with the adverse effects of this condition, this research indicates that patients' consciousness and knowledge about their disease and having the skills and motivation to follow the prescribed treatment can minimize some polypharmacy causes. Therefore, a close and trustful patientphysician relationship is significant to reduce polypharmacy. In this sense, healthcare professionals 
should coproduce the treatment experience with their patients, sharing decisions and responsibilities. They should also try to understand patients' needs, worries, and lifestyles. Moreover, a closer relationship with their physicians can encourage patients to follow their prescriptions and adopt a healthier lifestyle.

\section{Figure 2 - Possible initiatives to deal with some polypharmacy consequences}

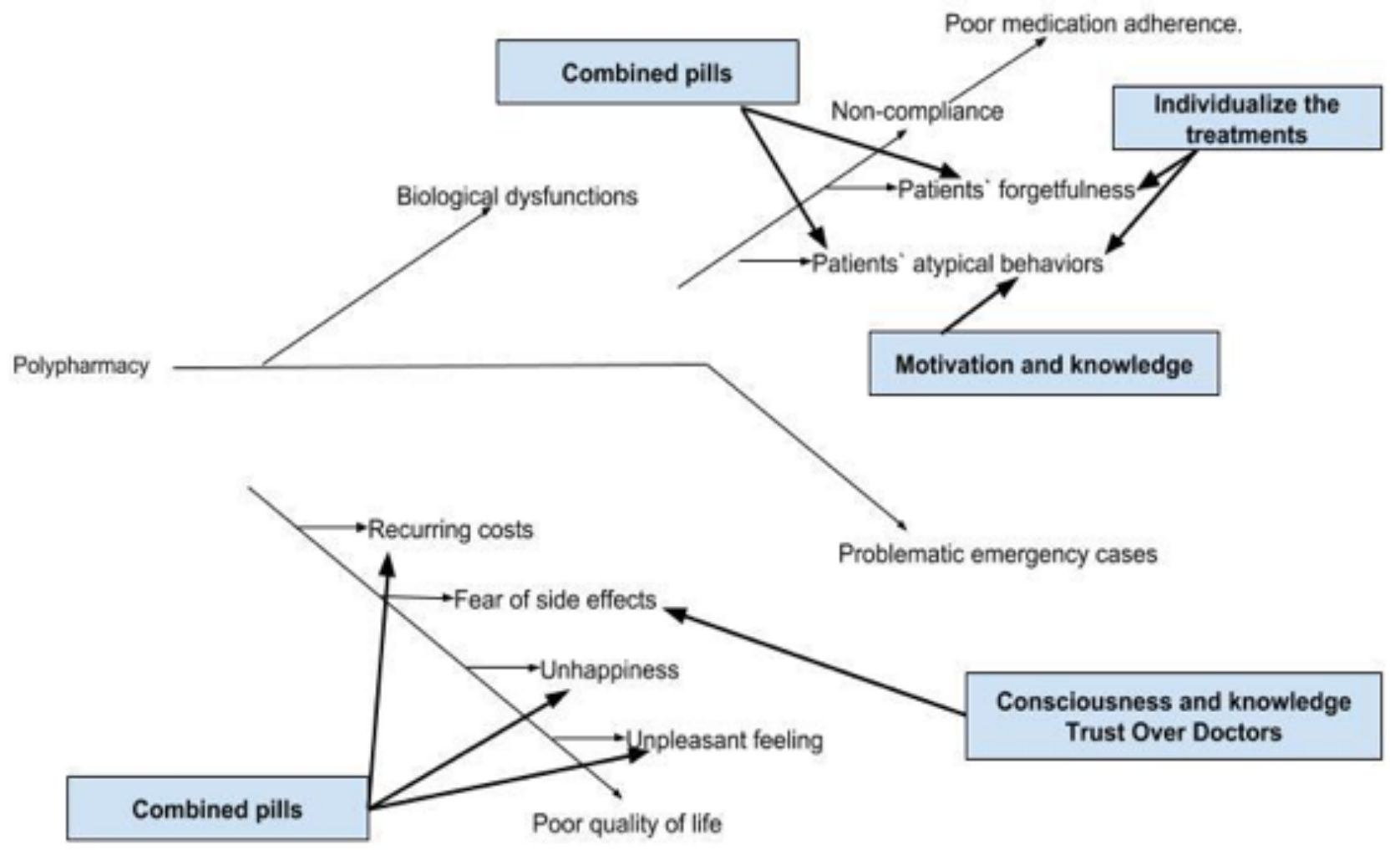

Source: Elaborated by the authors

A treatment coordinator could also help reduce polypharmacy when this condition results from multiple providers looking after the patient. In addition, lowering patients' daily medications will reduce some adverse effects like drug-drug interactions, and poor medication adherence, thereby improving patients' health outcomes. These improved health outcomes, in turn, may reduce healthcare services utilization and costs.

This research also suggests that combined pills can reduce the excessive number of daily drugs, recurring patients' costs, unhappiness, and unpleasant feelings regarding their treatment. Additionally, fewer medications will also reduce forgetfulness and increase patients' adherence and motivation to follow the prescribed therapy.

Some research limitations should be elucidated. We adopted a qualitative approach, and, therefore, these research findings cannot be generalized. Moreover, the interviewees were selected based on their availability. This convenience selection might limit the breadth and quality of the data. Finally, the number of interviewees is small since we could not find more people taking five or more daily medicines and willing to participate in this research.

However, this research is relevant to academics because it increases the knowledge about the non-clinical polypharmacy factors and possible initiatives to mitigate this condition. Researchers who want to explore the non-clinical perspective of polypharmacy may find this research valuable. This research is also essential because few studies focus on this subject in developing countries like Brazil. This research is relevant for public managers and governments since it reduces healthcare services utilization and costs. Therefore, it is also applicable to managers who work in insurance companies or private clinics and are committed to minimize companies' costs and improve patients' quality of life. To society, this study can help improve patients' quality of life and health condition since it reveals non-clinical factors associated with polypharmacy and brings ideas about how to deal with this situation and reduce the number of daily medicines intake.

This research proposed several interventions that physicians can use to manage polypharmacy, considering the dimensions of knowledge, skills, and motivation. However, future research could 
quantitatively investigate the initiatives proposed here to verify their effectiveness. Also, future research could focus on specific pathologies to identify differences regarding patients' behavior and initiatives to mitigate polypharmacy.

\section{References}

Abolhassani, N., Castioni, J., Marques-Vidal, P., Vollenweider, P., \& Waeber, G. (2017). Determinants of change in polypharmacy status in Switzerland: the population-based CoLaus study. European Journal of Clinical Pharmacology, 73(9), 1187-1194. https://doi.org/10.1007/s00228-017-2288-1

Anthierens, S., Tansens, A., Petrovic, M., \& Christiaens, T. (2010). Qualitative insights into general practitioners' views on polypharmacy. BMC Family Practice, 11. https://doi.org/ 10.1186/1471-2296-11-65

Aujoulat, I., Young, B., \& Salmon, P. (2012). The psychological processes involved in patient empowerment. Orphanet Journal of Rare Diseases, 7(Suppl 2), A31. https://doi.org/ 10.1186/1750-1172-7-s2-a31

Batalden, M., Batalden, P., Margolis, P., Seid, M., Armstrong, G., Opipari-Arrigan, L., \& Hartung, H. (2016). Coproduction of healthcare service. BMJ quality \& safety, 25(7), 509-517.

Benetos, A., Rossignol, P., Cherubini, A., Joly, L., Grodzicki, T., Rajkumar, C., Strandberg, T. E., \& Petrovic, M. (2015). Polypharmacy in the Aging Patient: Management of Hypertension in Octogenarians. Journal of the American Medical Association, 314(2), 170-180. https://doi.org/10.1001/ jama.2015.7517

Bradley, E. (2015). Carers and coproduction: Enabling expertise through experience? Mental Health Review Journal, 20(4), 232-241. https://doi.org/10.1108/MHRJ-05-2014-0016

Bradley, M. C., Fahey, T., Cahir, C., Bennett, K., O’Reilly, D., Parsons, C., \& Hughes, C. M. (2012). Potentially inappropriate prescribing and cost outcomes for older people: A cross-sectional study using the Northern Ireland Enhanced Prescribing Database. European Journal of Clinical Pharmacology, 68(10), 1425-1433. https://doi.org/10.1007/s00228-012-1249-y

Chan, K. W., Yim, C. K., \& Lam, S. S. K. (2010). Is customer participation in value creation a double-edged sword? Evidence from professional financial services across cultures. Journal of Marketing, 74(3), 4864. https://doi.org/10.1509/jmkg.74.3.48

Chase, R. B. (2010). Revisiting "Where Does the Customer Fit in a Service Operation?" In P. Maglio, C. A. Kieliszewski, \& J. C. Spohrer (Eds.), Handbook of Service Science (pp. 11-17). Springer. https:// doi.org/https://doi.org/10.1007/978-1-4419-1628-0_2

Combrinck, Y., van Wyk, N. C., \& Mogale, R. S. (2020). Nurses' professional dignity in private health care: a descriptive phenomenological study. International Nursing Review, 67(3), 395-402. https://doi.org/ 10.1111/inr.12602

Coulter, A. (2009). Implementing shared decision making in the UK A report for the Health Foundation. The Health Foundation, 1-50. http://www.health.org.uk

Craig, G. (2015). How insights into what matters to people can help us optimize medicines. Journal of Medicines Optimisation, 1(1), 16-18.

D’Avanzo, B., Agosti, P., Reeve, E., Pasina, L., Sabbà, C., Mannucci, P. M., \& Nobili, A. (2020). Views of medical practitioners about deprescribing in older adults: Findings from an Italian qualitative study. Maturitas, 134(January), 29-33. https://doi.org/10.1016/j.maturitas.2020.01.009

Dadfar, H., Brege, S., \& Semnani, S. S. E. (2013). Customer involvement in service production, delivery, and quality: the challenges and opportunities. International Journal of Quality and Service Sciences, 5(1), 46-65. https://doi.org/http://dx.doi.org/10.1108/17566691311316248 Downloaded

Dellande, S., Gilly, M. C., \& Graham, J. L. (2004). Gaining compliance and losing weight: the role of the service provider in health care services. Journal of Marketing, 68(3), 78-91. https://doi.org/10.1509/ jmkg.68.3.78.34764

Damali, U, Miller, J. L., Fredendall, L. D., Moore, D., \& Dye, C. J. (2016). Co-creating value using customer training and education in a healthcare service design. Journal of Operations Management, 47/48, 80-97. https://doi.org/10.1016/j.jom.2016.10.001

Duerden, M., \& Payne, R. (2013). Polypharmacy and medicines optimisation Making it safe and sound Authors. November,1-68. https://doi.org/10.13140/RG.2.1.1597.0726

Duffett, L. (2017). Patient engagement: What partnering with patient in research is all about. Thrombosis Research, 150, 113-120. https://doi.org/10.1016/j.thromres.2016.10.029

Endsley, S. (2018). Deprescribing unnecessary medications: A four-part process. Family Practice Management, 25(3), 28-32.

Frei, F. X. (2008). The four things a service business must get right. Harvard Business Review, 86(4).

Gupta, S. (2019). Polypharmacy in Clinical Practice. ARC Journal of Pharmaceutical Sciences, 5(1). https://doi.org/10.20431/2455-1538.0501001 
Guthrie, B., Makubate, B., Hernandez-Santiago, V., \& Dreischulte, T. (2015). The rising tide of polypharmacy and drug-drug interactions: Population database analysis 1995-2010. BMC Medicine, 13(1), 1-10. https://doi.org/10.1186/s12916-015-0322-7

Haque, R. (2009). ARMOR: A Tool to Evaluate Polypharmacy in Elderly Persons. Annals of Long-Term Care, 17(6), 26-30.

Hasan Ibrahim, A. S., Barry, H. E., \& Hughes, C. M. (2021). A systematic review of general practice-based pharmacists' services to optimize medicines management in older people with multimorbidity and polypharmacy. Family Practice, 1-15. https://doi.org/10.1093/fampra/cmaa146

Hee Yoon, M., Seog Yoon, T., \& Hyun Seo, J. (2004). Effects of contact employee supports on critical employee responses and customer service evaluation. Journal of Services Marketing, 18(5), 395-412. https://doi.org/10.1108/08876040410548311

Herr, M., Grondin, H., Sanchez, S., Armaingaud, D., Blochet, C., Vial, A., Denormandie, P., \& Ankri, J. (2017). Polypharmacy and potentially inappropriate medications: a cross-sectional analysis among 451 nursing homes in France. European Journal of Clinical Pharmacology, 73(5), 601-608. https:// doi.org/10.1007/s00228-016-2193-Z

Hirose, Y., Shikino, K., Ohira, Y., Matsuoka, S., Mikami, C., Tsuchiya, H., Yokokawa, D., Ikegami, A., Tsukamoto, T., Noda, K., Uehara, T., \& Ikusaka, M. (2021). Feedback of patient survey on medication improves the management of polypharmacy: a pilot trial. BMC Family Practice, 22(1), 1-8. https:// doi.org/10.1186/s12875-021-01396-x

Hoel, R. W., Giddings Connolly, R. M., \& Takahashi, P. Y. (2021). Polypharmacy Management in Older Patients. Mayo Clinic Proceedings, 96(1), 242-256. https://doi.org/10.1016/j.mayocp.2020.06.012

Hovstadius, B., Åstrand, B., \& Petersson, G. (2009). Dispensed drugs and multiple medications in the Swedish population: An individual-based register study. BMC Clinical Pharmacology, 9, 1-10. https:// doi.org/10.1186/1472-6904-9-11

Jansen, J., Naganathan, V., Carter, S. M., McLachlan, A. J., Nickel, B., Irwig, L., Bonner, C., Doust, J., Colvin, J., Heaney, A., Turner, R., \& McCaffery, K. (2016). Too much medicine in older people? Deprescribing through shared decision making. BMJ (Online), 353(June), 1-6. https://doi.org/10.1136/bmj.i2893

Knowles, S., Hays, R., Senra, H., Bower, P., Locock, L., Protheroe, J., Sanders, C., \& Daker-White, G. (2018). Empowering people to help speak up about safety in primary care: Using codesign to involve patients and professionals in developing new interventions for patients with multimorbidity. Health Expectations, 21(2), 539-548. https://doi.org/10.1111/hex.12648

Jaspers, S., \& Steen, T. (2020). The sustainability of outcomes in temporary coproduction, International Journal of Public Sector Management, 33(1), 62-77. https://doi.org/10.1108/IJPSM-05-2019-0124

Köberlein, J., Gottschall, M., Czarnecki, K., Thomas, A., Bergmann, A., \& Voigt, K. (2013). General practitioners' views on polypharmacy and its consequences for patient health care. BMC Family Practice, 14. https://doi.org/10.1186/1471-2296-14-119

Larson, E. B. (2001). General internal medicine at the crossroads of prosperity and despair: Caring for patients with chronic diseases in an aging society. Annals of Internal Medicine, 134(10), 997-1000. https://doi.org/10.7326/0003-4819-134-10-200105150-00013

Mair, A., Wilson, M., \& Dreischulte, T. (2020). Addressing the challenge of polypharmacy. Annual Review of Pharmacology and Toxicology, 60, 661-681. https://doi.org/10.1146/annurevpharmtox-010919-023508

Marsilio, M., Fusco, F., Gheduzzi, E., \& Guglielmetti, C. (2021). Coproduction Performance Evaluation in Healthcare. A Systematic Review of Methods, Tools and Metrics. International Journal of Environmental Research and Public Health, 18(7), 3336.

Masnoon, N., Shakib, S., Kalisch-Ellett, L., \& Caughey, G. E. (2017). What is polypharmacy? A systematic review of definitions. BMC Geriatrics, 17(1), 1-10. https://doi.org/10.1186/s12877-017-0621-2

McColl-Kennedy, J. R., Vargo, S. L., Dagger, T. S., Sweeney, J. C., \& Kasteren, Y. V. (2012). Health care customer value cocreation practice styles. Journal of service research, 15(4), 370-389.

Montiel-Luque, A., Núñez-Montenegro, A. J., Martín-Aurioles, E., Canca-Sánchez, J. C., Toro-Toro, M. C., González-Correa, J. A., \& Group, O. B. O. T. P. R. (2017). Medication-related factors associated with health-related quality of life in patients older than 65 years with polypharmacy. PLoS ONE, 12(2), 116. https://doi.org/10.1371/journal.pone.0171320

Mustak, M., Jaakkola, E., \& Halinen, A. (2013). Customer participation and value creation: A systematic review and research implications. Managing Service Quality, 23(4), 341-359. https://doi.org/ 10.1108/MSQ-03-2013-0046

O’Mahony, D., O'Sullivan, D., Byrne, S., O'connor, M. N., Ryan, C., \& Gallagher, P. (2015). STOPP/START criteria for potentially inappropriate prescribing in older people: Version 2. Age and Ageing, 44(2), 213-218. https://doi.org/10.1093/ageing/afu145

Ostrom, E., Parks, R. B., Whitaker, G. P., \& Percy, S. L. (1978). The public service production process: a 
framework for analyzing police services. Policy Studies Journal, 7, 381.

Palumbo, R. (2016). Contextualizing coproduction of health care: a systematic literature review. International Journal of Public Sector Management, 29(1), 72-90. https://doi.org/10.1108/ IJPSM-07-2015-0125

Pappa, E., Kontodimopoulos, N., Papadopoulos, A. A., Tountas, Y., \& Niakas, D. (2011). Prescribed-drug utilization and polypharmacy in a general population in Greece: Association with sociodemographic, health needs, health-services utilization, and lifestyle factors. European Journal of Clinical Pharmacology, 67(2), 185-192. https://doi.org/10.1007/s00228-010-0940-0

Patterson, P. G., Cowley, E., \& Prasongsukarn, K. (2006). Service failure recovery: The moderating impact of individual-level cultural value orientation on perceptions of justice. International Journal of Research in Marketing, 23(3), 263-277. https://doi.org/10.1016/j.ijresmar.2006.02.004

Payne, A. F., Storbacka, K., \& Frow, P. (2008). Managing the cocreation of value. Journal of the academy of marketing science, 36(1), 83-96.

Riker, G. I., \& Setter, S. M. (2013). Polypharmacy in Older Adults at Home. Home Healthcare Nurse, 31(2), 65-77. https://doi.org/10.1097/nhh.0b013e31827f43b2

Rozenfeld, S. (2003). Prevalência, fatores associados e mau uso de medicamentos entre os idosos: uma revisão. Cadernos de Saúde Pública, 19(3), 717-724. https://doi.org/10.1590/ $\underline{\mathrm{s} 0102-311 \times 2003000300004}$

Rosentraub, M. S., \& Sharp, E. B. (1981). Consumers as producers of social services: Coproduction and the level of social services. Southern Review of Public Administration, 502-539.

Secoli, S. R., Marquesini, E. A., Fabretti, S. de C., Corona, L. P., \& Romano-Lieber, N. S. (2018). Selfmedication practice trend among the Brazilian elderly between 2006 and 2010: SABE study. Revista Brasileira de Epidemiologia, 21(Suppl 2). https://doi.org/10.1590/1980-549720180007.supl.2

Spanjol, J., Cui, A. S., Nakata, C., Sharp, L. K., Crawford, S. Y., Xiao, Y., \& Watson-Manheim, M. B. (2015). Coproduction of prolonged, complex, and negative services: an examination of medication adherence in chronically ill individuals. Journal of Service Research, 18(3), 284-302.

Spinewine, A., Schmader, K. E., Barber, N., Hughes, C., Lapane, K. L., Swine, C., \& Hanlon, J. T. (2007). Appropriate prescribing in elderly people: how well can it be measured and optimised? Lancet, 370(9582), 173-184. https://doi.org/10.1016/S0140-6736(07)61091-5

Steen, T., \& Brandsen, T. (2020). Coproduction during and after the COVID-19 Pandemic: Will It Last?, Public Administration Review, 80(5), 851-855.

Stewart, D., Gibson-Smith, K., MacLure, K., Mair, A., Alonso, A., Codina, C., Cittadini, A., FernandezLlimos, F., Fleming, G., Gennimata, D., Gillespie, U., Harrison, C., Junius-Walker, U., Kardas, P., Kempen, T., Kinnear, M., Lewek, P., Malva, J., McIntosh, J., ... Wiese, B. (2017). A modified Delphi study to determine the level of consensus across the European Union on the structures, processes and desired outcomes of the management of polypharmacy in older people. PLOS ONE, 12(11), 1-17. https:// doi.org/10.1371/journal.pone.0188348

Stryker, S. (2006). Traditional Symbolic Interactionism, Role Theory, and Structural Symbolic Interactionism: The Road to Identity Theory. Handbook of Sociological Theory, 211-231. https:// doi.org/10.1007/0-387-36274-6_11

Tecklenborg, S., Byrne, C., Cahir, C., Brown, L., \& Bennett, K. (2020). Interventions to Reduce Adverse Drug Event-Related Outcomes in Older Adults: A Systematic Review and Meta-analysis. Drugs and Aging, 37(2), 91-98. https://doi.org/10.1007/s40266-019-00738-w

Youngdahl, W. E., Kellogg, D. L., Nie, W., \& Bowen, D. E. (2003). Revisiting customer participation in service encounters: Does culture matter? Journal of Operations Management, 21(1), 109-120. https:// doi.org/10.1016/S0272-6963(02)00070-0 